\title{
RHEOLOGICAL APPROACHES SUITABLE FOR INVESTIGATING STARCH AND PROTEIN PROPERTIES RELATED TO COOKING QUALITY OF DURUM WHEAT PASTA
}

\author{
ALESSANDRA MARTI ${ }^{1,3}$, KOUSHIK SEETHARAMAN ${ }^{2}$ and MARIA AMBROGINA PAGANI ${ }^{1}$ \\ 1Department of Food, Environmental and Nutritional Sciences (DeFENS), Università degli Studi di Milano, via Celoria, 2, 20133 Milan, Italy \\ ${ }^{2}$ Department of Food Science, University of Guelph, Guelph, ON, Canada
}

\author{
${ }^{3}$ Corresponding author. \\ TEL: +39-02-50316640; \\ FAX: +39-02-50316672; \\ EMAIL: alessandra.marti@unimi.it
}

Received for Publication April 15, 2012

Accepted for Publication November 15, 2012

10.1111/jfq.12015

\begin{abstract}
Starch and protein properties of semolina and pasta samples were investigated using MVAG and GPT, which are generally used for starch and common wheat flour characterization. From two semolina, which have different starch and protein content and pasta-making qualities, four spaghetti samples were produced and dried using low- or high-temperature drying. Starch and protein arrangements in dried pasta were related to pasta cooking behavior. The tests discriminated semolinas according to their technological quality. Good quality semolina (A) exhibited a high pasting temperature, low hot viscosity, and high and earlier protein aggregation properties. In regard to pasta, when dried at a low temperature, spaghetti from sample A showed lower cooking loss than pasta from poor quality semolina (B), which is probably related to the low starch swelling and a strong network. The use of HT cycle lowered the differences in cooking quality and starch and protein properties related to the raw-materials features.
\end{abstract}

\section{PRACTICAL APPLICATIONS}

The development of a rapid method for evaluating semolina quality and how it relates to starch, protein properties and pasta cooking quality is of great interest for the pasta-making industry. This research highlights that MVAG and GPT tests are able to discriminate semolina according to their technological quality in a short time and using a low amount of sample. In addition, the tests gave useful information for understanding the effect of both raw-materials characteristics and drying conditions on starch and protein macromolecules in determining the final cooking quality.

\section{INTRODUCTION}

Good cooking quality in pasta from durum wheat semolina is commonly characterized by high firmness, absence of stickiness and low cooking loss, characteristics that express high cooking and overcooking tolerance (D'Egidio et al. 1990). This behavior is strongly related to the compact structure of the matrix, characterized by a continuous network formed by coagulated gluten proteins, entrapping swollen and gelatinized starch granules (Resmini and Pagani 1983; Cunin et al. 1995). The extent of protein coagulation and starch gelatinization phenomena, and consequently the overall cooking quality of the final product, is greatly affected not only by the native properties of semolina, especially protein quantity and quality (D'Egidio et al. 1990; Feillet and Dexter 1996), but also by the temperaturemoisture conditions applied during drying (De Noni and Pagani 2010).

The effect of drying cycles on pasta cooking quality has been investigated by using several approaches suitable for describing events at the macroscopic level, such as organic loss into cooking and rinsing water (D'Egidio et al. 1990, 1993), and textural properties of cooked pasta (D'Egidio et al. 1993; Petitot et al. 2009). Other techniques can provide information at the molecular level. As far as starch structure is concerned, differential scanning calorimetry and X-ray 
diffractometry are used to quantify the endothermic melting and loss of crystallinity of starch granules (Guler et al. 2002; Petitot et al. 2009), whereas the amylose amount leached into cooking water can be related to pasta stickiness (Grant et al. 1993). Focusing on proteins, the changes induced by drying temperatures were monitored by measuring solubility, thiol accessibility, surface hydrophobicity, gel electrophoresis and reversed-phase high-performance liquid chromatography of protein components (De Stefanis and Sgrulletta 1990; Aktan and Khan 1992; Lamacchia et al. 2007; Petitot et al. 2009; Bruneel et al. 2010; Bonomi et al. 2012). All these approaches are time-consuming and require sophisticated instruments and well-trained technicians. Consequently, they are scarcely usable in the context of industrial pasta-making.

The main objective of the present study was to verify the suitability of two empirical and simple rheological approaches, as the tests based on MVAG and GPT (Brabender GmbH and Co. KG, Duisburg, Germany), to detect the starch and protein arrangements in dried pasta, which can differ according to durum wheat variety and pastamaking conditions, and therefore, give information suitable for predicting pasta cooking behavior. In order to verify the capacity of the instruments to detect these differences, the study was limited to only two semolina samples with different composition and pasta-making performances. They were used to prepare spaghetti, which were dried applying two drying cycles, at LT and HT. MVAG and GPT tests were used to provide insight into the effect of raw materials and drying cycle on starch and protein in relation to pasta cooking behavior.

\section{MATERIALS AND METHODS}

\section{Semolina Characterization}

Two commercial semolina blends (particle size: more than 70\% between 400 and $250 \mu \mathrm{m}$, Molino Grassi, Parma, Italy), labeled sample A and sample B, were used. Semolina samples were characterized by standard methods: (1) in terms of moisture content (AACC 2001; 44.15-02); (2) protein content (AOAC 1999; 920.87); (3) gluten content (AACC 2001; 38.12); (4) lipid content (AACC 2001; 30.25); (5) total starch (AACC 2001; 76.13); (6) damaged starch (AACC 2001; 76-30); (7) alpha-amylase activity (AACC 2001; 22.02); (8) and alveographic indices $\mathrm{W}$ and P/L (UNI 10453 1995).

\section{Pasta Preparation}

Spaghetti samples were produced in the pilot plant $(50 \mathrm{~kg} / \mathrm{h})$ of DiSTAM, University of Milan. Semolina and water $($ dough moisture $=35 \%)$ were mixed $(15 \mathrm{~min})$ and extruded in a continuous press (extrusion pressure $=10$ $11 \mathrm{MPa}$ ) (Braibanti, Milano, Italy). A jacket with cold water kept the dough temperature at about 40C. The extruder ended with a Teflon die (diameter hole of $1.60 \mathrm{~mm}$ ) and spaghetti-shaped pasta was obtained. Each sample was dried in an experimental drying cell (Braibanti) using an LT (50C $\max / 14 \mathrm{~h}$ ) and an HT profile (90C max/8 h), according to D'Egidio et al. (1993). All samples were stored at room temperature until analyzed. For the rheological approaches, pasta was finely ground (less than $250 \mu \mathrm{m}$ ) in a laboratory mill (IKA Universalmuhle M20, Janke and Kunkel GmbH \& Co. KG, IKA Laborteknic, Staufen Germany).

\section{MVAG}

Semolina or uncooked ground pasta (12 g) was dispersed in distilled water $(100 \mathrm{~mL})$. The pasting properties were evaluated in triplicate and under constant conditions (speed: $250 \mathrm{rpm}$; sensitivity: $300 \mathrm{cmgf}$ ) and the temperature profile was changed as follows: heating from 30 to $95 \mathrm{C}$, holding at $95 \mathrm{C}$ for $30 \mathrm{~min}$, cooling from 95 to $50 \mathrm{C}$, holding at $50 \mathrm{C}$ for $30 \mathrm{~min}$ and cooling to $30 \mathrm{C}$. The heating/cooling rate was 3.0C/min. Viscosity was expressed in Brabender units (B.U.) and the following indices were considered: (1) pasting temperature (temperature at which an initial increase in viscosity occurs); (2) maximum viscosity achieved during the heating cycle; (3) breakdown (the decrease in viscosity during the first holding period, calculated as the maximum viscosity minus the viscosity at the starting cooling period); (4) final viscosity; (5) and setback (the increase in viscosity during cooling, calculated as the difference between the final viscosity and the viscosity at the starting cooling period). Measurements were performed in triplicate.

\section{GPT}

Semolina or uncooked ground pasta samples $(9 \mathrm{~g})$ and distilled water $(9 \mathrm{~g})$ were weighed into the sample cup of the GPT (Brabender GmbH and Co KG). Sample temperature was maintained at $35 \mathrm{C}$ by circulating water through the jacketed sample cup. The paddle was set to rotate at $3,000 \mathrm{rpm}$ and each test ran for $15 \mathrm{~min}$. Torque recorded $(n=3)$ was expressed in Brabender equivalents (B.E.) and the maximum torque and the peak maximum time were considered.

\section{Solids Loss into Cooking Water}

Cooking loss was evaluated by determining the amount of solids lost in cooking water (D'Egidio et al. 1990). An aliquot of pasta sample $(10 \mathrm{~g})$ was cooked in $100 \mathrm{~mL}$ of boiling water with no salt added. Spaghetti was cooked at the optimal cooking time $(8 \mathrm{~min}$, determined according to 
TABLE 1. SEMOLINA CHARACTERIZATION

\begin{tabular}{lcc}
\hline & Sample A & Sample B \\
\hline Moisture (g/100 g) & 13.5 & 14.0 \\
Protein (g/100 g d.b.) & 14.3 & 10.4 \\
Gluten (g/100 g) & 13.2 & 8.2 \\
Lipid (g/100 g) & 1.1 & 0.8 \\
Starch (g/100 g d.b.) & 75.1 & 81.7 \\
Damaged starch (g/100 g total starch) & 6.3 & 5.6 \\
Alpha-amylase activity (IU/g d.b.) & 0.78 & 0.44 \\
Alveographic W (*10-4 J) & 205 & 152 \\
\hline
\end{tabular}

d.b., dry basis.

D'Egidio and Nardi 1996). After cooking, pasta was drained and the weight increase of pasta (water absorption) during cooking was evaluated by weighing the pasta before and after cooking, and was expressed as percent weight gain with respect to the weight of uncooked pasta. The cooking water was brought back to the initial $100 \mathrm{~mL}$ volume, and $25 \mathrm{~mL}$ was dried to constant weight at $105 \mathrm{C}$. Results $(n=4)$ were expressed as g solids/100 g of dry pasta.

\section{Statistical Analysis}

Two-way analysis of variance was performed using Microsoft Excel (Microsoft, Redmond, VA).

\section{RESULTS AND DISCUSSION}

\section{Semolina Samples}

Semolina A and B were characterized by different composition and rheological performances, as shown in Table 1. Sample A had high protein and gluten content, and alveographic W index higher than $200 \times 10^{-4} \mathrm{~J}$, a value commonly associated with good pasta-making properties (D'Egidio et al. 1990; Landi and Guarneri 1992).

According to the MVAG test, starch in sample A started to develop viscosity more than 10C later compared with sample B and exhibited lower viscosity values in every part of the test, suggesting lower swelling tendency (Table 2). The difference in hot viscosity between the samples could be related to several factors, such as total starch, damaged starch content, alpha-amylase activity, and protein or lipid content

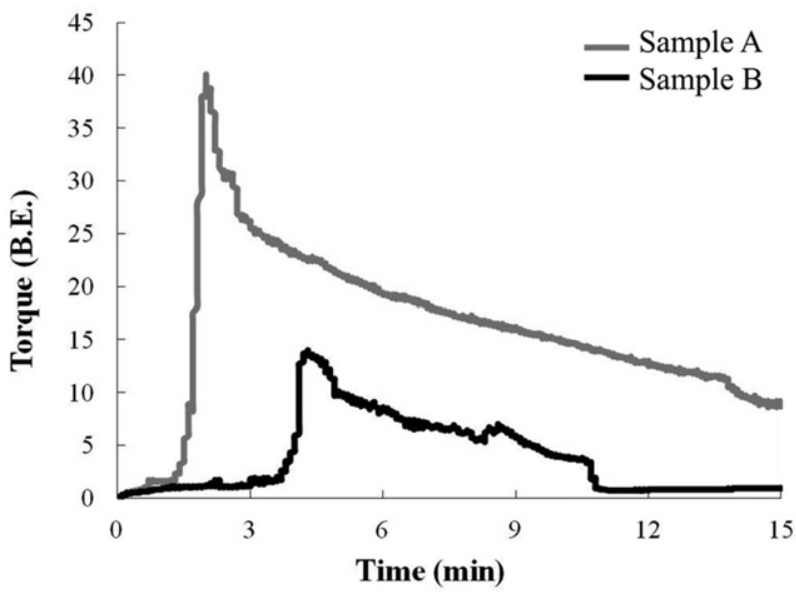

FIG. 1. GPT ON SEMOLINA SAMPLES

(Table 1) as suggested by several researchers (Mariotti et al. 2005; Leon et al. 2006; Singh et al. 2011). Moreover, this trend could likely be related to particular starch characteristics, such as the arrangement of starch polymers inside the granule (Marti et al. 2012), which is responsible for a more or less propensity to hydrate and swell.

The GPT is a new rapid shear-based method for discriminating gluten quality (Chandi and Seetharaman 2012). The instrument records the time to reach the peak torque during the formation of a gluten structure. Semolina A and B exhibited significantly different GPT profiles, suggesting differences in gluten aggregation behavior (Fig. 1). Sample A was characterized by a rapid buildup in torque to a sharply defined peak, followed by a rapid breakdown (Fig. 1). This profile highlighted the greater ability for sample A to create a strong protein network when compared to sample B. This is in agreement with the alveograph index (Table 2).

\section{Pasta Characterization}

Good pasta cooking quality is assured by the formation of a continuous and strengthened network of coagulated gluten proteins, which entraps the starch macromolecules, limiting their swelling and solubilization into the cooking water (Resmini and Pagani 1983). Therefore, the amount of mate-

TABLE 2. MVAG AND GPT ON SEMOLINA SAMPLES

\begin{tabular}{|c|c|c|c|c|c|c|c|}
\hline & \multicolumn{5}{|l|}{ MVAG } & \multicolumn{2}{|l|}{ GPT } \\
\hline & $\begin{array}{l}\text { Pasting } \\
\text { temperature }(\mathrm{C})\end{array}$ & $\begin{array}{l}\text { Maximum viscosity } \\
\text { during heating (B.U.) }\end{array}$ & $\begin{array}{l}\text { Breakdown } \\
\text { (B.U.) }\end{array}$ & $\begin{array}{l}\text { Final viscosity } \\
\text { (B.U.) }\end{array}$ & $\begin{array}{l}\text { Setback } \\
\text { (B.U.) }\end{array}$ & $\begin{array}{l}\text { Maximum } \\
\text { torque (B.E.) }\end{array}$ & $\begin{array}{l}\text { Peak maximum } \\
\text { time ( } \min )\end{array}$ \\
\hline Sample A & $81.3 \pm 0.4$ & $210.0 \pm 1.4$ & 0 & $559.5 \pm 10.6$ & $354.0 \pm 12.7$ & $38.0 \pm 3.0$ & $2.0 \pm 0.2$ \\
\hline Sample B & $68.9 \pm 1.2$ & $361.0 \pm 18.4$ & $27.5 \pm 2.1$ & $900.5 \pm 53.0$ & $567.0 \pm 36.8$ & $12.6 \pm 0.8$ & $4.9 \pm 0.7$ \\
\hline
\end{tabular}


TABLE 3. PASTA COOKING BEHAVIOR

\begin{tabular}{lll}
\hline & Cooking loss $(\mathrm{g} / 100 \mathrm{~g})$ & Water absorption $(\mathrm{g} / 100 \mathrm{~g})$ \\
\hline Pasta A-LT & $2.82 \pm 0.05$ & $117.5 \pm 1.1$ \\
Pasta B-LT & $3.22 \pm 0.06$ & $128.0 \pm 2.7$ \\
Pasta A-HT & $3.71 \pm 0.09$ & $122.8 \pm 2.3$ \\
Pasta B-HT & $4.15 \pm 0.05$ & $123.0 \pm 1.0$ \\
\hline
\end{tabular}

$\mathrm{HT}$, high-temperature drying cycles; LT, low-temperature drying cycle.

rial that has leached into cooking water or stuck to the pasta surface is frequently used to define the cooking quality of semolina pasta (D'Egidio and Nardi 1996). Regardless of the drying conditions, sample A gave a product with good cooking attributes, showing a lower tendency to leaching (low cooking loss) than spaghetti from semolina B (Table 3). There was not a significant interaction between semolina and drying conditions $(P<0.05)$. The higher protein and gluten quantity (Table 1 ) and the lower tendency of starch granules to swell in sample A (Table 2) likely assured a macromolecular organization in the corresponding pasta suitable for assuring lower solids losses during cooking.

Interesting information on the particular starch and protein structures in dried pasta according to semolina quality and drying conditions are given by MVGA and GPT tests. Pasting properties of pasta were affected by both semolina quality and drying conditions (Fig. 2) and the interaction between them $(P<0.05)$. Spaghetti from good quality semolina (sample A) exhibited lower viscosity values than pasta from poor quality semolina (sample B) regardless of the drying conditions (Table 4). The low starch hydration and gelatinization tendency in pasta A could be attributed to the starch structure being able to stand up to cooking stresses, accounting for lower cooking losses (Table 3). The results also suggested a different porosity and compactness between the samples, confirming water absorption data (Table 3). The use of HT cycle lowered the differences in cooking quality related to the quality of raw materials, in agreement with the literature (D'Egidio et al. 1993). Both HT dried spaghetti exhibited a particular pasting profile, characterized by the absence of the peak viscosity during the heating phase, suggesting that starch granules were entrapped inside a matrix limiting their

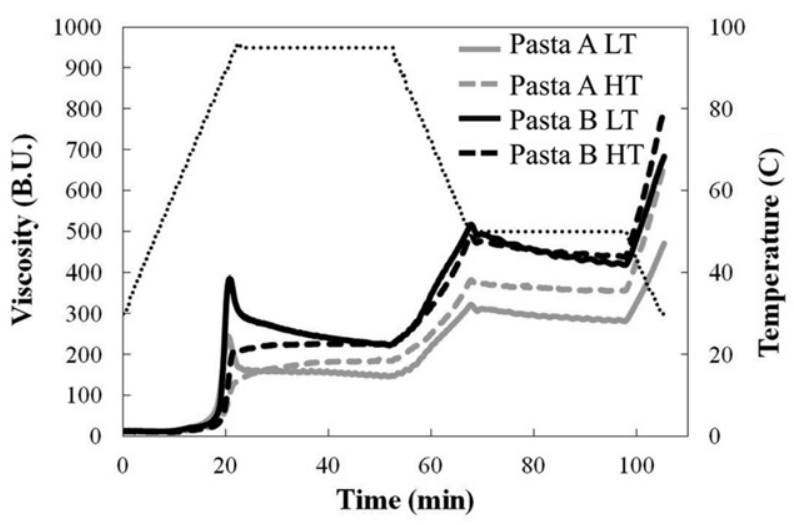

FIG. 2. MVAG TEST ON UNCOOKED PASTA SAMPLES

$H T$, high-temperature drying cycles; LT, low-temperature drying cycle.

swelling and subsequent gelatinization and solubilization in the aqueous system. The presence of a plateau during the period at $95 \mathrm{C}$ could also indicate the formation of a new macromolecular organization, difficult to be hydrated, probably due to a relevant compactness, as detected by textural approaches (Petitot et al. 2009).

GPT, using pasta samples, gave information about the gluten matrix strength of spaghetti as a consequence of the effect of both semolina quality and drying cycle (Fig. 3). When dried at LT, pasta A from good quality semolina showed a higher GPT torque than Pasta B-LT, both quite different in profile from semolina samples. This profile suggests the presence of a structured protein network in Pasta A-LT, still able to react during the mixing phase of the test. This property could limit starch swelling during MVAG (Fig. 2) and account for the lower cooking loss (Table 3). However, the measurement of torque during the GPT suggested that in Pasta A-LT proteins were organized in an uncoagulated matrix. On the contrary, Pasta B-LT did not show any torque during the test, suggesting the presence of a very weak structure before cooking.

For both HT dried spaghetti, no torque was measured by the instrument, confirming that the higher the drying temperature, the greater the protein denaturation, creating an indeformable matrix. In addition, the HT drying cycle lowered the differences in protein matrix/aggregate between the samples, in agreement with D'Egidio et al. (1993).

TABLE 4. MVAG TEST ON PASTA SAMPLES

\begin{tabular}{lllcll}
\hline & $\begin{array}{l}\text { Pasting } \\
\text { temperature (C) }\end{array}$ & $\begin{array}{l}\text { Maximum } \\
\text { viscosity (B.U.) }\end{array}$ & $\begin{array}{l}\text { Breakdown } \\
(\text { B.U.) }\end{array}$ & $\begin{array}{l}\text { Final viscosity } \\
(\text { B.U.) }\end{array}$ & $\begin{array}{l}\text { Setback } \\
\text { (B.U.) }\end{array}$ \\
\hline Pasta A-LT & $68.4 \pm 0.3$ & $242.5 \pm 3.5$ & $93.5 \pm 4.9$ & $449.0 \pm 29.7$ & $300.0 \pm 31.1$ \\
Pasta B-LT & $69.3 \pm 0.5$ & $381.0 \pm 7.1$ & $145.0 \pm 24.0$ & $693.0 \pm 12.7$ & $457.0 \pm 4.2$ \\
Pasta A-HT & $78.6 \pm 0.6$ & $186.5 \pm 2.1$ & 0 & $667.0 \pm 9.9$ & $483.0 \pm 9.9$ \\
Pasta B-HT & $76.5 \pm 0.7$ & $241.5 \pm 20.5$ & 0 & $814.5 \pm 23.3$ & $576.5 \pm 6.4$ \\
\hline
\end{tabular}

$\mathrm{HT}$, high-temperature drying cycles; LT, low-temperature drying cycle. 


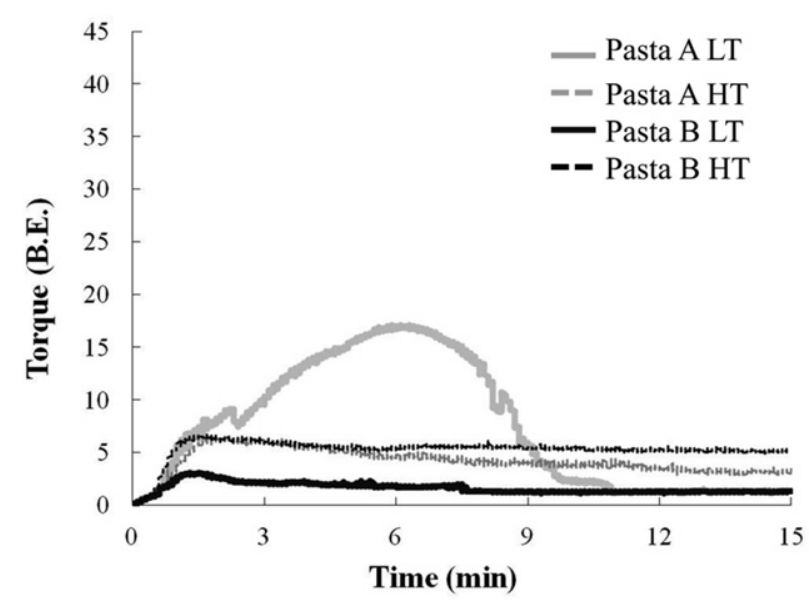

FIG. 3 GPT ON UNCOOKED PASTA SAMPLES

$H T$, high-temperature drying cycles; LT, low-temperature drying cycle.

\section{CONCLUSIONS}

In conclusion, good quality semolina exhibited higher pasting temperature, lower hot viscosity, and higher and faster protein aggregation tendency. After pasta-making, pasta LT drying cycle exhibited lower starch swelling and a structured protein network, accounting for the good cooking behavior (high water absorption and low solids loss) at the optimal cooking time. The HT drying cycle induced other new macromolecular interactions, lowering the role of semolina quality in pasta cooking behavior. These preliminary results show that MVAG and GPT tests could be successfully applied for (1) discriminating good and poor semolina quality, using a low amount of sample; and (2) understanding the effect of both raw-materials characteristics and drying conditions on starch and protein macromolecules in determining the final cooking quality. These differences are related not only to the quantity of starch or protein, but also to the quality associated with them. Based on these results, further studies are underway with larger sample numbers.

\section{NOMENCLATURE}

GPT, GlutoPeak Test; HT, high-temperature drying cycles; LT, low-temperature drying cycle; MVAG, MicroViscoAmyloGraph.

\section{ACKNOWLEDGMENTS}

Authors wish to acknowledge Dr. Jens Dreisoerner for his constructive comments on this paper and Dr. Rosita Caramanico for assistance with making pasta samples at
CRA-SCV. A.M. is the grateful recipient of a postdoctoral fellowship from the European Social Fund.

\section{REFERENCES}

AACC. 2001. Approved Methods of American Association of Cereal Chemists, American Association of Cereal Chemists, St. Paul, MN.

AKTAN, B. and KHAN, K. 1992. Effect of high-temperature drying of pasta on quality parameters and on solubility, gel-electrophoresis, and reversed-phase high-performance liquid-chromatography of protein-components. Cereal Chem. 69, 288-295.

AOAC. 1999. Official Methods of Analysis, Association of Official Analytical Chemists, Gaithersburg, MD.

BONOMI, F., D'EGIDIO, M.G., IAMETTI, S., MARENGO, M., MARTI, A., PAGANI, M.A. and RAGG, E. 2012.

Structure-quality relationship in commercial pasta:

A molecular glimpse. Food Chem. 135, 348-355.

BRUNEEL, C., PAREYT, B., BRIJS, K. and DELCOUR, J.A. 2010. The impact of the protein network on pasting and cooking properties of dry pasta products. Food Chem. 120, 371-378.

CHANDI, G.K. and SEETHARAMAN, K. 2012. Optimization of gluten peak tester: A statistical approach. J. Food Qual. 35, 69-75.

CUNIN, C., HANDSCHIN, S., WALTHER, P. and ESCHER, F. 1995. Structural changes of starch during cooking of durum wheat pasta. LWT 28, 323-328.

D'EGIDIO, M.G. and NARDI, S. 1996. Textural measurements of cooked pasta. In Pasta and Noodle Technology (J.E. Kruger, R.B. Matsuo and J.W. Dick, eds.) pp. 133-156, American Association Cereal Chemists, St. Paul, MN.

D'EGIDIO, M.G., MARIANI, B.M., NARDI, S., NOVARO, P. and CUBADDA, R. 1990. Chemical and technological variables and their relationships: A predictive equation for pasta cooking quality. Cereal Chem. 67, 275-281.

D'EGIDIO, M.G., MARIANI, B.M., NARDI, S. and NOVARO, P. 1993. Viscoelastograph measures and total organic matter test: Suitability in evaluating textural characteristics of cooked pasta. Cereal Chem. 70, 67-72.

DE NONI, I. and PAGANI, M.A. 2010. Cooking properties and heat damage of dried pasta as influenced by raw material characteristics and processing conditions. Crit. Rev. Food Sci. Nutr. 50, 465-472.

DE STEFANIS, E. and SGRULLETTA, D. 1990. Effects of high-temperature drying on technological properties of pasta. J. Cereal Sci. 12, 97-104.

FEILLET, P. and DEXTER, J.E. 1996. Quality requirements of durum wheat for semolina milling and pasta production. In Pasta and Noodle Technology (J.E. Kruger, R.B. Matsuo and J.W. Dick, eds.) pp. 95-131, American Association Cereal Chemists, St. Paul, MN.

GRANT, L.A., DICK, J.W. and SHELTON, D.R. 1993. Effects of drying temperature, starch damage, sprouting, and additives 
on spaghetti quality characteristics. Cereal Chem. 70, 676-684.

GULER, S., KOKSEL, H. and NG, P.K.W. 2002. Effects of industrial pasta drying temperatures on starch properties and pasta quality. Food Res. Int. 35, 421-427.

LAMACCHIA, C., DI LUCCIA, A., BAIANO, A., GAMBACORTA, G., LA GATTA, B., PATI, S. and LA NOTTE, E. 2007. Changes in pasta proteins induced by drying cycles and their relationship to cooking behaviour. J. Cereal Sci. 46, 58-63.

LANDI, A. and GUARNERI, R. 1992. Durum wheat and pasta industries: Twenty years of achievement in science and technology. In Cereal Chemistry and Technology: A Long Past and a Bright Future, Proceedings of the 9th Cereal and Bread Congress (P. Feillet, ed.) pp. 139-142, Institut National de la Recherché Agronomique, Montpellier, France.

LEON, A.E., BARRERA, G.N., PEREZ, G.T., RIBOTTA, P.D. and ROSELL, C.M. 2006. Effect of damaged starch levels on flour-thermal behaviour and bread staling. Eur. Food Res. Technol. 224, 187-192.
MARIOTTI, M., ZARDI, M., LUCISANO, M. and PAGANI, M.A. 2005. Influence of the heating rate on the pasting properties of various flours. Starch/Stärke 57, 564-572.

MARTI, A., PAGANI, M.A. and SEETHARAMAN, K. 2012. Affinity for iodine of semolina matrices. J. Cereal Sci. 56, 516-518.

PETITOT, M., BROSSARD, C., BARRON, C., LARRÉ, C., MOREL, M.H. and MICARD, V. 2009. Modification of pasta structure induced by high drying temperatures. Effects on the in vitro digestibility of protein and starch fractions and the potential allergenicity of protein hydrolysates. Food Chem. 116, 401-412.

RESMINI, P. and PAGANI, M.A. 1983. Ultrastructure studies of pasta: A review. Food Microbiol. 2, 1-12.

SINGH, S., SINGH, N. and MACRITCHIE, F. 2011. Relationship of polymeric proteins with pasting, gel dynamic- and dough empirical-rheology in different Indian wheat varieties. Food Hydrocolloid. 25, 19-24.

UNI 10453. 1995. Grano duro e semole. Determinazione delle caratteristiche reologiche mediante alveografica. UNI, Ente Nazionale Italiano di Unificazione, Milano, Italy. 